\title{
Gambaran Motorik Anak Yang Menggunakan Alat Permainan Edukatif Di TK DCC 2019
}

\author{
Festy Ladyani Mustofa $^{1}$, Supriyati $^{2}$, Mohamad Rheza Firmansyah Zamzami $^{3 *}$ \\ ${ }^{1}$ Fakultas Kedokteran Universitas Malahayati, \\ ${ }^{2}$ Fakultas Kedokteran Universitas Malahayati, \\ ${ }^{3}$ Fakultas Kedokteran Universitas Malahayati,mohamad.r.zamzami@gmail.com.
}

\begin{abstract}
ABSTRAK
Keterlambatan tumbuh kembang anak di indonesia berdasarkan Depkes mencapai angka 16\% dari total keseluruhan balita di indonesia. Berbagai macam faktor dapat mempengaruhi tumbuh kembang anak salah satunya yaitu stimulasi alat permainan edukatif (APE). Jumlah keterlambatan tumbuh kembang di Indonesia masih tinggi meskipun jumlah APE meningkat. Mengetahui gambaran tingkat perkembangan motorik anak usia prasekolah yang menggunakan alat permainan edukatif di TK Dian Cipta Cendikia (DCC) Global School tahun 2019. Penelitian deskriptif kuantitatif dengan pendekatan pengamatan data dan observasi. Jenis data yang diperoleh yaitu data primer dan sekunder. Cara pengumpulan data melalui pengamatan data hasil rapor TK B dan hasil Denver II serta observasi APE. Penelitian dilakukan selama bulan November 2019 . Sampel yang diambill meliputi seluruh siswa TK B DCC Global School yang berjumlah enam siswa yang diambil dengan teknik total sampling. Hasil menunjukkan bahwa satu dari total enam siswa dinyatakan gagal dalam mengerjakan satu dari 12 gugus aktivitas Denver II usia 4-6 tahun. Satu siswa tidak dapat menggunakan APE motorik kasar berupa tangga paralel dengan baik serta berdasarkan hasil rapor terdapat satu siswa yang mendapatkan nilai belum berkembang dalam kategori mengenal rambu lalu lintas yang ada di jalan. Distribusi frekuensi penggunaan APE di TK DCC Global School sebanyak 91,7\% baik. Gambaran perkembangan motorik anak berdasarkan hasil rapor meliputi 54,2\% berkembang sesuai yang diharapkan dan berdasarkan hasil Denver II yaitu $100 \%$ normal.
\end{abstract}

Kata kunci : perkembangan motorik, prasekolah, permainan edukatif.

\section{ABSTRACT}

Child development's delay in Indonesia based on the Indonesia Ministry of Health was 16\% of a total toddler in Indonesia. The various factors affecting the child's development, such as the stimulation of the educative game instrument (EGI). Increase of the use of EGI in other countries proportional to the child's development aspect but not in Indonesia. To know the overview of the motor development level of preschool-aged children towards the educative game instrument at Dian Cipta Cendekia (DCC) Global School Kindergarten 2019. A descriptive quantitative study by using an observational approach was performed. The data were collected using a review of the school report, the use of the EGI, and the ability to follow the commands based on Denver II categories. This research was done during November 2019. There were six samples from class b taken using a total sampling method. 1 of 6 children failed by following 1 of 12 activities based on Denver II. One of them couldn't use the climbing frames properly, and based on the school report, 1 of 6 children stated as not developing yet by knowing the traffic sign. The level of using EGI proportional to the child's development aspect. The frequency distribution of the use of EGI shown 91,7\% good. An overview of motor development level based on school report shown 54,2\% normal development and 100\% normal by Denver II.

Keywords : motor development, preschool, educative game.

*Author Korespondensi : Mohamad Rheza Firmansyah Zamzami, Fakultas Kedokteran Malahayati, mohamad.r.zamzami@gmail.com,082113338496.

\section{PENDAhULUAN}

Anak tidak memisahkan antara bermain dan belajar. Bagi anak, seluruh aktivitasnya adalah bermain yang juga mencakup belajar, kesenangannya, dan metode bagaimana mereka mengenal dunia. Bermain yaitu kegiatan yang menimbulkan kesenangan tanpa memikirkan hasil akhir serta bersifat tanpa tekanan dari luar. Dalam bermain, anak memerlukan media yang mendukung dalam permainannya. ${ }^{1}$

Anak memerlukan berbagai variasi permainan untuk kesehatan fisik, mental sosial 
dan perkembangan emosinya. ${ }^{2}$ Selain itu disebutkan bahwa di dalam permainan anak mencurahkan perhatian, perasaan dan pikiran pada proses bermain serta sifat dan bentuk alat permainannya. Dengan demikian anak-anak akan belajar mengenali dan menjajaki lingkungannya. ${ }^{3}$

Pengertian alat permainan adalah semua alat yang digunakan anak untuk memenuhi naluri bermainnya. Alat permainan edukatif adalah jenis permainan yang mengandung nilai pendidikan yang berfungsi untuk merangsang daya imajinasi anak dalam proses perkembangan kongnitif, proses kegiatannya yaitu pemberian stimulasi sehingga dapat meningkatkan aspek perkembangan dalam proses tumbuh kembang anak yang dinilai dari perkembangan motorik kasar, motorik halus, kemampuan bicara dan bahasa serta kemampuan sosisalisasi dan kemandirian. ${ }^{4,5}$ Pembagian jenis jenis APE dapat dikategorisasikan berdasarkan banyak sedikitnya tenaga yang diperlukan dan berdasarkan penemunya.

Pembagian jenis-jenis APE berdasarkan alat permainan yang diciptakan oleh para ahli, yaitu : APE menurut Peabody, Montessori, Crussenaire, dan Frobe. $^{6}$ Selain itu, jenis permainan edukatif motorik yang diterapkan dapat dibedakan antara jenis permainan yang membutuhkan aktivitas fisik atau bermain aktif dan jenis permainan yang membutuhkan fisik sedikit atau bermain pasif. ${ }^{7}$ Jenis permainan yang sesuai untuk perkembangan motorik kasar anak antara lain permainan yang melatih kemampuan melompat, memanjat, lari, lompat tali dan lompat jauh. ${ }^{8}$

Perkembangan dan pertumbuhan merupakan proses yang berjalan beriringan. Perkembangan adalah bertambahnya kemampuan (skill) struktur dan fungsi tubuh yang lebih kompleks, dalam pola yang teratur, dan dapat diramalkan sebagai hasil dari proses pematangan/maturitas. Perkembangan dijelaskan juga di dalam Peraturan Menteri Pendidikan dan Kebudayaan Republik Indonesia No 137 Tahun 2014 tentang Standar Nasional Pendidikan Anak Usia Dini pada pasal 7 ayat 3 yang berbunyi "Perkembangan anak sebagaimana dimaksudkan disini merupakan integrasi dari perkembangan aspek nilai agama dan moral, fisik, motorik, kognitif bahasa, dan sosial emosional, serta seni. ${ }^{9}$

Dinas Kesehatan RI menyebutkan bahwa di Indonesia pada tahun 2010 jumlah anak yang diberikan permainan edukatif pada tahun 2009 mencapai 23.000 jiwa, pada tahun 2010 mencapai 24.120 jiwa dan pada tahun 2011 mencapai 25.100 jiwa. Berdasarkan laporan dari Departemen Kesehatan Republik Indonesia cakupan pelayanan kesehatan balita dalam deteksi tumbuh kembang balita yang mengalami gangguan tumbuh kembang anak di Indonesia sebanyak 45,7\%. Depkes RI tahun 2006 menyatakan $16 \%$ balita Indonesia mengalami gangguan perkembangan, baik perkembangan motorik halus dan kasar. ${ }^{10}$

\section{METODOLOGI}

Penelitian ini merupakan penelitian deskriptif kuantitatif dengan menggunakan pendekatan pengamatan data dan observasi dimana peneliti mencari tahu gambaran tingkat perkembangan motorik anak usia prasekolah dalam penggunaan alat permainan edukatif . Teknik sampel yang digunakan yaitu total sampling. Penelitian ini dilaksanakan pada bulan November 2019.

Populasi dalam penelitian ini adalah anak anak usia antara 3-6 tahun di TK DCC Global School Bandar Lampung. Dalam penelitian ini sampel yang diambil yaitu seluruh siswa TK B DCC Global School yang berjumlah enam orang. Anak-anak akan diperiksa perkembangannya berdasarkan pengamatan hasil rapor dan kemampuan melaksanakan gugus aktivitas berdasarkan alat ukur Denver II serta observasi dalam peggunaan APE. Denver II adalah salah satu dari metode skrining terhadap kelainan perkembangan anak, tes ini bukanlah tes diagnostik atau tes IQ. Di dalam aspek perkembangan motorik kasar anak usia 4 hingga 6 tahun terdapat enam gugus aktivitas motorik dan pada motorik halus terdapat enam gugus aktivitas motorik .

Hasil penilaian pada Denver II, meliputi jumlah gugus aktivitas yang lulus, gagal, 
menolak dan tidak ada kesempatan. Jumlah total dari penilaian awal tersebut akan diakumulasikan dan dikategorikan apakah termasuk kategori normal, suspect, atau tidak dapat diuji .

Data yang diambil hanya data yang memenuhi kriteria inklusi (1) Anak sehat usia 36 tahun, (2) Terdapat persetujuan (informed consent) dari orang tua atau guru pengajar, (3) Memiliki rapor. Kriteria eksklusi pada penelitian ini yaitu (1) Anak kelas TK A, (2) Anak dengan kelainan perkembangan / anak berkebutuhan khusus

Teknik analisis data pada penelitian kuantitatif ini menggunakan uji univariat. Data yang diperoleh dianalisa dengan SPSS menggunakan uji univariat dimana data akan dicari distribusi frekuensinya lalu dijelaskan hasilnya secara deskriptif.

\section{HASIL DAN PEMBAHASAN}

Subjek penelitian ini terdiri dari tujuh siswa TK B DCC Global School dimana satu siswa tidak memenuhi kriteria inklusi penelitian sehingga jumlah siswa yang diamati menjadi enam. Distribusi frekuensi usia dan jenis kelamin di TK B DCC Global School dapat dilihat pada tabel 1 .

Data menunjukan bahwasanya terdapat emapt orang sisiwi dan dua orang siswa di TK DCC Global School yang termauk kedalam kriteria inklusi penelitian. TK DCC Global School Bandar Lampung memiliki 12 APE yang mendukung perkembangan motorik anak baik kasar maupun halus. Anak yang diberi intervensi APE tampak senang dengan jenis permainan yang diberikan.

Tabel 1. Distribusi Frekuensi Usia dan Jenis Kelamin Di TK DCC Global School

\begin{tabular}{lccccc}
\hline \multirow{2}{*}{$\begin{array}{c}\text { Jenis } \\
\text { Kelamin }\end{array}$} & $\mathbf{4 5 , 5}$ Tahun & $\mathbf{5 , 5}$ Tahun $\mathbf{- 6}$ Tahun & $\mathbf{> 6}$ Tahun & Frekuensi & Persentase \\
\hline Laki-Laki & 1 & & & & \\
Perempuan & 2 & 1 & 0 & 2 & $33.3 \%$ \\
\hline Total & 3 & 1 & 1 & 4 & $66.7 \%$ \\
\hline
\end{tabular}

Tabel 2. Gambaran Tingkatan Penggunaan APE Motorik

\begin{tabular}{|c|c|c|c|c|c|}
\hline \multirow[b]{2}{*}{ No } & \multirow[b]{2}{*}{ APE } & \multicolumn{3}{|c|}{ Keterangan } & \multirow[b]{2}{*}{ Frekuensi } \\
\hline & & Kurang Baik & Baik & Sangat Baik & \\
\hline 1 & Ayunan & 0 & 6 & 0 & 6 \\
\hline 2 & Perosotan & 0 & 6 & 0 & 6 \\
\hline 3 & Tangga Paralel & 1 & 4 & 1 & 6 \\
\hline 4 & Lompat Jinggit & 0 & 6 & 0 & 6 \\
\hline 5 & Terowongan & 0 & 6 & 0 & 6 \\
\hline 6 & Sepak Bola & 0 & 6 & 0 & 6 \\
\hline 7 & Tali Tambang & 0 & 6 & 0 & 6 \\
\hline 8 & Jembatan Goyang & 0 & 6 & 0 & 6 \\
\hline 9 & Jungkat-Jungkit & 0 & 6 & 0 & 6 \\
\hline 10 & Buku Gambar & 0 & 4 & 2 & 6 \\
\hline 11 & Balok Kayu & 0 & 5 & 1 & 6 \\
\hline \multirow[t]{2}{*}{12} & Puzzle & 0 & 5 & 1 & 6 \\
\hline & Total & 1 & 66 & 5 & 72 \\
\hline \multicolumn{3}{|c|}{$\begin{array}{l}\text { Penggunaan APE di TK DCC Globa } \\
\text { School tidak hanya digunakan pada saat waktı } \\
\text { istirahat, tetapi juga pada saat pembelajarar }\end{array}$} & \multicolumn{3}{|c|}{$\begin{array}{l}\text { dimana guru menggunakan APE sebagai alat } \\
\text { peraga. Durasi yang digunakan untuk } \\
\text { penggunaan APE adalah tiga jam. APE yang }\end{array}$} \\
\hline
\end{tabular}


diamati meliputi APE motorik kasar dan halus yang digunakan baik di dalam ruangan maupun luar ruangan. Di dalam penelitian, hampir seluruh siswa dapat menggunakan APE tersebut dengan baik, tetapi ada satu siswa yang kurang bisa menggunakan APE berupa tangga paralel serta puzzle. Siswa pada awalnya menolak untuk menggunakan APE tersebut, lalu setelah dibujuk, siswa baru menggunakan APE tersebut. Di dalam penggunaan puzzle siswa merasa kebingungan untuk mengerjakannya meskipun sudah diberikan sedikit contoh oleh guru sehingga siswa tidak melanjutkan bermain puzzle tersebut. Sedangkan dalam penggunaan tangga paralel, siswa hanya dapat berdiri hingga undakan pertama dan enggan melanjutkannya.
Penilaian

penggunaan

APE

dikategorikan berdasarkan tingkat kemampuan penggunaannya. Hasil yang diperoleh seperti yang tertera pada tabel 2 . Interpretasi dari tabel tersebut menunjukkan bawah terdapat satu orang siswa yang kurang baik dalam menggunakan tangga paralel meskipun demikian terdapat dua orang anak yang sangat mahir dalam menggambar.

Pengamatan data selanjutnya yaitu melalui rapor TK B DCC Global School yang memiliki delapan macam kriteria aktivitas pada aspek perkembangan motorik. Kriteria dan penilaian hasil aktivitas dari enam orang siswa tersebut dapat dilihat pada tabel 3 .

Tabel 3 Gambaran Penilaian Aktivitas Motorik Berdasarkan Hasil Rapor

\begin{tabular}{llccccc}
\hline No & \multicolumn{1}{c}{ Aktivitas } & \multicolumn{3}{c}{ Keterangan } & Frekuensi \\
\cline { 3 - 7 } & & BSB & BSH & MB & BB & \\
\hline $\mathbf{1}$ & $\begin{array}{l}\text { Melakukan gerakan melompat, meloncat, } \\
\text { dan berlari secara terkoordinasi }\end{array}$ & 3 & 2 & 1 & 0 & 6 \\
$\mathbf{2}$ & $\begin{array}{l}\text { Melempar sesuatu secara terarah } \\
\mathbf{3}\end{array}$ & 2 & 3 & 1 & 0 & 6 \\
$\mathbf{4}$ & $\begin{array}{l}\text { Melakukan gerakan antisipasi } \\
\text { Menendang sesuatu secara terarah }\end{array}$ & 4 & 2 & 0 & 0 & 6 \\
$\mathbf{5}$ & $\begin{array}{l}\text { Mengkoordinasi mata dan tangan untuk } \\
\text { melakukan hal yang rumit }\end{array}$ & 1 & 4 & 1 & 0 & 6 \\
$\mathbf{6}$ & $\begin{array}{l}\text { Melakukan gerakan manipulatif untuk } \\
\text { menghasilkan suatu bentuk dengan } \\
\text { menggunakan berbagai media }\end{array}$ & 0 & 5 & 1 & 0 & 6 \\
$\mathbf{7}$ & $\begin{array}{l}\text { Mengekspresikan diri dengan berkarya seni } \\
\text { menggunakan berbagai media }\end{array}$ & 2 & 3 & 1 & 0 & 6 \\
$\mathbf{8}$ & $\begin{array}{l}\text { Mengenal rambu lalu lintas yang ada di } \\
\text { jalan }\end{array}$ & 0 & 3 & 2 & 1 & 6 \\
\hline
\end{tabular}

Keterangan

BSH : Berkembang Sangat Baik

BSB : Berkembang Sangat Baik

MB : Mulai Berkembang

BB : Belum Berkembang

Rapor TK DCC Global School memiliki delapan aktivitas motorik yang dinilai. Semua aktivitas motorik tersebut dinilai cukup mewakili perkembangan yang diharapkan di dalam usia anak prasekolah. Berdasarkan penilaian hasil rapor diketahui bahwa terdapat beberapa aktivitas dimana beberapa siswa dapat melakukannya dengan sangat baik terutama pada aktivitas motorik kasar. Pada aktivitas lainnya, siswa sudah dapat berkembang sesuai dengan usianya meskipun masih ada satu siswa yang belum berkembang sesuai dengan yang diharapkan. Pada aktivitas mengenal rambu lalu lintas di jalan raya bahkan terdapat satu orang siswa yang masih belum dapat memahaminya, sehingga dinyatakan belum berkembang. 
Berdasarkan hasil rapor, dinyatakan bahwasanya lima dari enam orang siswa sudah berkembang sesuai dengan usianya dan terdapat satu orang siswa yang berada dalam tahapan masih berkembang.

Hasil penilaian perkembangan berdasarkan Denver II didasarkan kepada jumlah gugus aktivitas yang berhasil dilakukan. Peneliti mengintervensi siswa untuk melakukan 12 aktivitas motorik yang terdiri dari enam aktivitas motorik kasar dan enam aktivitas motorik halus sesuai dengan kriteria usia anak 46 tahun pada Denver II. Hasil penilaian pada Denver II, meliputi jumlah gugus aktivitas yang lulus, gagal, menolak dan tidak ada kesempatan. Jumlah total dari penilaian awal tersebut akan diakumulasikan dan dikategorikan apakah termasuk kategori normal, suspect, atau tidak dapat diuji. Tabel 4 merupakan hasil penilaian masing masing gugus aktivitas dengan empat macam kriteria penilaian.

Tabel 4 Gugus Aktivitas Motorik Usia Anak 4-6 Tahun Berdasarkan Denver II

\begin{tabular}{|c|c|c|c|c|c|c|}
\hline \multirow[t]{2}{*}{ No } & \multirow[t]{2}{*}{ Gugus Aktivitas } & \multicolumn{4}{|c|}{ Keterangan } & \multirow[t]{2}{*}{ Jumlah } \\
\hline & & $\mathbf{P}$ & $\mathbf{F}$ & NO & $\mathbf{R}$ & \\
\hline 1 & Melompat dengan 1 kaki & 6 & 0 & 0 & 0 & 6 \\
\hline 2 & Berdiri 1 kaki 3 detik & 6 & 0 & 0 & 0 & 6 \\
\hline 3 & Beridri 1 kaki 4 detik & 6 & 0 & 0 & 0 & 6 \\
\hline 4 & Berdiri 1 kaki 5 detik & 6 & 0 & 0 & 0 & 6 \\
\hline 5 & Berjalan tumit ke jari kaki & 6 & 0 & 0 & 0 & 6 \\
\hline 6 & Berdiri 1 kaki 6 detik & 6 & 0 & 0 & 0 & 6 \\
\hline 7 & Menggambar orang 3 bagian & 6 & 0 & 0 & 0 & 6 \\
\hline 8 & Mencontoh tulisan + & 6 & 0 & 0 & 0 & 6 \\
\hline 9 & Memilih garis yang lebih panjang & 5 & 1 & 0 & 0 & 6 \\
\hline 10 & Mencontoh kotak yang ditunjukan & 6 & 0 & 0 & 0 & 6 \\
\hline 11 & Menggambar orang 5 bagian & 6 & 0 & 0 & 0 & 6 \\
\hline 12 & Mencontoh kotak & 6 & 0 & 0 & 0 & 6 \\
\hline & Total & 71 & 1 & 0 & 0 & 72 \\
\hline \multicolumn{7}{|c|}{ Keterangan } \\
\hline $\mathrm{P}$ & Pass / Lulus & & & & & \\
\hline $\mathrm{F}$ & : Fail / Gagal & & & & & \\
\hline $\mathrm{NO}$ & : No Opportunity/ Tidak Ada Kese & & & & & \\
\hline $\mathrm{R}$ & Refusal / Menolak & & & & & \\
\hline
\end{tabular}

Berdasarkan hasil Denver II, dinyatakan bahwasanya terdapat satu orang siswa yang gagal / fail dalam melakukan aktivitas memilih garis yang lebih panjang sehingga mendapatkan caution (Peringatan) , meskipun demikian perkembangan motorik siswa di TK DCC Global School masih dalam kategori normal karena telah lulus mengerjakan gugus kegiatan atau hanya terdapat satu kriteria yang fail.
Berdasarkan hasil tabel tersebut maka dapat disimpulkan bahwa kemampuan anak dalam menggunakan APE berjalan proposional terhadap perkembangan motorik anak prasekolah di TK B DCC Global School Bandar Lampung bulan November tahun 2019.

Hasil ini didukung oleh penelitian sebelumnya oleh dr. Permana SpAn, tahun 2007 dengan penilaian menggunakan cronbach test berkesimpulan bahwa ada perbedaan perkembangan anak pada kelompok anak pra 
sekolah yang mendapat stimulasi dan kelompok anak pra sekolah yang tidak mendapat stimulasi dengan alat permainan edukatif.

\section{KESIMPULAN DAN SARAN}

Berdasarkan hasil penelitian dan pembahasan tentang gambaran tingkat perkembangan motorik pada anak usia prasekolah yang menggunakan alat permainan edukatif di TK Dian Cipta Cendikia (DCC) Global School Bandar Lampung tahun 2019 dari hasil pengamatan data serta observasi langsung terhadap siswa kelas TK B, maka diketahui:

1. Distribusi frekuensi penggunaan APE di TK DCC Global School sebanyak 6,9\% sangat baik, 91,7\% baik , dan 1,4\% kurang baik.

2. Distribusi gambaran perkembangan motorik anak di TK DCC Global School berdasarkan hasil rapor meliputi $27 \%$ berkembang sangat baik, 54,2 \% berkembang sesuai yang diharapkan, 16,7\% dalam tahapan masih berkembang dan 2,1 $\%$ belum berkembang.

3. Distribusi gambaran perkembangan motorik anak di TK DCC Global School berdasarkan hasil Denver II yaitu $100 \%$ normal.

Hasil penelitian secara keseluruhan menyatakan bahwa anak yang mendapatkan nilai berkembang sesuai harapan atau lebih pada rapornya serta nilai lulus pada tes Denver II diketahui dapat menggunakan APE secara baik. Sedangkan anak yang mendapatkan nilai masih berkembang lebih dari satu dan kegagalan pada salah satu aspek Denver II diketahui mengalami kesulitan dalam menggunakan APE. Meskipun demikian jika kita merujuk kepada hasil interpretasi Denver II dimana anak dikatakan normal jika semua kategori gugus aktivitas dinyatakan lulus atau terdapat satu yang gagal.

Hasil penelitian ini membuktikan pernyataan Soetjiningsih (2016) bahwa alat permainan edukatif adalah alat permainan yang mengandung nilai nilai pendidikan yang dapat membantu anak dalam pengembangan kognitif, soisal, motoric dan emosionalnya sehingga mencapai perkembangan yang optimal.. Saran bagi orang tua, agar lebih memperhatikan dan selektif dalam pemberian APE yang sesuai dengan usia anak sehingga proses pertumbuhan dan perkembangan anak terutama perkembangan motorik dapat terjadi secara optimal. Saran bagi TK DCC Global School agar pihak sekolah dapat membuat rapor yang penjabarannya berdasarkan Denver II sebagai alat ukur baku untuk perkembangan. Peneliti juga menyarankan untuk melengkapi APE dan mendampingi siswa di dalam penggunaannya terutama APE motorik kasar sehingga penggunaan APE di TK tersebut akan optimal. Saran bagi penelitian selanjutnya untuk menggunakan metodologi yang lain seperti analitik kuantitatif dengan jumlah sample lebih besar sehingga dapat mengetahui hubungan dan kekuatan korelasi antara penggunaan APE terhadap perkembangan aspek motorik anak usia prasekolah.

\section{UCAPAN TERIMA KASIH}

Peneliti mengucapkan terima kasih kepada Allah SWT yang telah memberikan rahmat dan pertolongannya sehingga penelitian ini dapat berjalan dengan lancar. Peneliti juga mengucapkan terima kasih kepada semua pihak yang berperan dalam pelaksanaan penelitian ini, terutama kepada guru dan siswa TK DCC Global School Bandar Lampung sebagai responden dalam penelitian ini.

\section{REFERENSI}

1. Hurlock EB. Perkembangan Anak. Edk 6 . Jakarta: Erlangga; 2013.

2. Soetjiningsih. Tumbuh Kembang Anak. Edk 2. Jakarta: EGC; 2016.

3. Khobir A. Upaya Mendidik Anak Melalui Permainan Edukatif. Forum Tarbiyah, 2009; Vol. 7(2): 197

4. Sain S, Ismanto A, Babaka A. Pengaruh Alat Permainan Edukatif Terhadap Aspek Perkembangan Pada Anak Pra Sekolah Di Wilayah Puskesmas Ondong Kabupaten Kepulauan Riau Tagulandang Biaro. Jurnal eNERS (eNS.). 2013. Vol. 1(1):16-20.

5. Syamsuardi. Penggunaan Alat Permainan Edukatif (APE) Di Taman Kanak-Kanak Paud Polewali Kecamatan Tanete Riattang Barat Kabupaten Bone. Jurnal Publikasi Pendidikan. 2012. Vol. 2(1): 59-67.

6. Hasnida. Media Pembelajaran Kreatif Mendukung Pembelajaran Pada Anak Usia 
Dini. Jakarta Timur : PT Luxima Metro Media; 2015.

7. Maghfiroh L. Permainan Edukatif dalam Pembelajaran Anak di TK Terpadu Tarbiyatul Athfal Jepara [skripsi]. Yogyakarta: Fakultas Tarbiyah, Jurusan PAI Universitas Islam Negeri SUKA; 2010.

8. Mukhtar N. Penggunaan Alat Permainan Edukatif Dalam Menstimulasi Perkembangan Fisik-Motorik Anak Usia Dini. Jurnal Program Studi PGRA, 2018; Vol. 4(2): 125-138.

9. Rahma D. Penggunaan Alat Permainan Edukatif Untuk Mendukung Perkembangan Anak Usia 56 Tahun Di Paud Al Fikri [skripsi]. Pontianak : Universitas Tanjungpura; 2017.

10. Siddik, MF. Darsih. Hubungan Penggunaan Alat Permainan Edukatif Dengan Perkembangan Anak Usia 3-5 Tahun Di Paud Uswatun Hasanah Sleman Yogyakarta; Jurnal Pendidikan,2015. Vol 1:10 